\title{
Em nós: hipertexto e literatura
}

Miguel Rettenmaier*

Ligar não é ler.

Marc Guillaume

De início, gostaria de fazer uma pequena proposta, a qual, de alguma forma, motiva este trabalho: que não nos percamos, na leitura do texto literário, no dinamismo excessivo da vida atual, intimamente associada às tecnologias e aos computadores. Presumivelmente não há microtoxinas em nossa circulação, o que nos obrigaria, como Case, de Neouromancer, de Gibson, a correr contra o tempo pela vida em busca de determinado antídoto. Se o corpo é a carne, como bem sabe o protagonista do romance, e a carne tem lá suas exigências, pensemos que podemos e devemos, em dados momentos, ter o tempo a nosso favor. E isso implica a liberdade de pensar e sentir com maior acuidade certas coisas num tempo presente, mesmo sob as demandas instantâneas do tempo real. Em outras palavras: experimentar a possibilidade de existir diferentemente numa atualidade cujas relações entre informação e comunicação fundamentam-se na articulação de dois poderosos elementos intimamente associados: a conexão e a comutação.

No que se refere à conexão, a língua portuguesa oferece uma agradável relação semântica em torno da homonímia da expressão "nós", articulada tanto como pronome quanto como substantivo plural, num jogo entre etimologias absolutamente distintas. Essa articulação entre as expressões é proposta por Alckmar dos Santos na obra Leituras de nós: ciberespaço e literatura, de 2003. Nessa obra, pronome e substantivo são elementos refratários na constituição da identidade nos processos de subjetivação, tanto à "totalidade inútil e distante" de uma multiplicidade indiscriminada e incontrolada de informações, quanto à vertigem da fragmentação do "fechamento individualista em si mesmo". Nesse sentido, a dicção metafórica do texto de Alckmar dos Santos repara em Osíris, o deus despedaçado, e em Adam Kadmom, personagem da obra de MiloradPavitch, $O$ dicionário Kazar, como imagens representativas de uma vital recostura das identidades quando repartidas e espalhadas em cacos. Da mesma forma, Santos propõe uma circunstância que ilustra a comunicação por fragmentos entre pontos além de si: o dilema dos náufragos trocando

\footnotetext{
* Professor da Universidade de Passo Fundo-RS, Graduação e Mestrado em Letras. mrettenmaier@hotmail.com
} 
garrafas na busca de recomposição de "uma identidade que se dê como percurso de si próprio”.

Esses náufragos terão, assim, de apossar-se dessas partes das histórias de outros, chegadas ao sabor e ao acaso das marés e dos ventos; fazer delas partes da sua história e fazer da sua pedaços das histórias de outros; propor uma narrativa multiforme, plural, em movimento, que não apague sua individualidade, e também não se resuma a ela apenas. A partir daí, sua vida inteira muda de sentido: não mais os sentidos outorgados e contados por uma mensagem original e primeira, mas os sentidos que eles são capazes de inventar com os materiais, imagens, idéias e histórias que outros lhes dão, que eles tiram de sua precária memória, nessa trama de nós e pontos infindáveis, prenhes de sentidos possíveis. (2003, p. 20).

A noção de um sujeito movente, conectado e, portanto, provisório, é base para a cibercultura da maneira como é apreciada e antevista por Pierre Lévy. Nessa linha cada sujeito se integra a um imenso e indefinido hipercorpo:

Meu corpo pessoal é a atualização temporária de um enorme hipercorpo híbrido, social, tecnobiológico. O corpo contemporâneo assemelha-se a uma chama. Freqüentemente é minúsculo, isolado, separado, quase imóvel. Mais tarde, corre para fora de si mesmo, intensificado pelos esportes e pelas drogas, funciona como um satélite, lança algum braço virtual bem alto em direção ao céu, ao longo de redes de interesse e de comunicação. Prende-se então ao corpo público e arde com o mesmo ardor, brilha com a mesma luz que outros corpos-chamas. Retorna em seguida, transformado, a uma esfera quase privada, e assim sucessivamente, ora aqui, ora em toda a parte, ora em si, ora misturado. Um dia, separa-se completamente do hipercorpo e se extingue. (1996, p. 33).

A conexão é base também para desafiadoras teorias do conhecimento, como o conectivismo, de Siemens, para quem o principal equívoco ou limitação do behaviorismo, do cognitivismo e do construtivismo é decorrência de princípios teóricos que não relacionam a tecnologia à cognição humana: a noção de que o conhecimento se dá "dentro" da pessoa.

A central tenet of most learning theories is that learning occurs inside a person. Even social constructivist views, which hold that learning is a socially enacted process, promotes the principality of the individual (and her/his physical presence - i.e. brain-based) in learning. These theories do not address learning that occurs outside of people (i.e. learning that is stored and manipulated by technology). They also fail to describe how learning happens within organizations. (2004) ${ }^{1}$.

${ }^{1} \mathrm{Um}$ dos eixos (ou dogmas) centrais da maioria das teorias de aprendizagem é que a aprendizagem ocorre dentro da pessoa. Mesmo a visão construtivista social, que defende que a aprendizagem é um processo social, promove o principado do indivíduo (e seu/sua presença física - i.e. baseado no cérebro) na aprendizagem. Estas teorias não abordam a aprendizagem que ocorre fora da pessoa (aprendizagem que é armazenada e manipulada através da tecnologia). Eles também falham em descrever como a aprendizagem acontece nas organizações.(tradução nossa). 
Siemens considera o sujeito aprendente como alguém situado num sistema colaborativo no qual a sua atuação permita tanto o desenvolvimento de seu conhecimento quanto o aprendizado dos outros componentes da rede. Esse processo de interação enriqueceria ilimitadamente as próprias fontes do ambiente no qual se armazenam e se manipulam as informações por meio da ação de síntese. Para o teórico,a capacidade de sintetizar e reconhecer conexões e padrões seria, nesse novo contexto, uma valiosa habilidade. Da mesma forma, para operar com as redes digitais é fundamental a competência de auto-organização por parte do sujeito, como elemento atuante no coletivo colaborativo. Se o ponto inicial da conexão é individual, sua existência cognoscente, contudo, apenas se compõe quanto integrada ao coletivo.

O saber, agora, pelo que aponta a teoria de Siemens, encontra dependência quanto ao que está "fora" do sujeito; o exterior ao sujeito, contudo, que pode ser por ele redefinido quando relacionado a outros saberes, numa rede que envolve campos, ideias e comunidades polinizadas.

\begin{abstract}
Connectivism is the integration of principles explored by chaos, network, and complexity and self-organization theories. Learning is a process that occurs within nebulous environments of shifting core elements - not entirely under the control of the individual. Learning (defined as actionable knowledge) can reside outside of ourselves (within an organization or a database), is focused on connecting specialized information sets, and the connections that enable us to learn more are more important than our current state of knowing. (2004). ${ }^{2}$
\end{abstract}

Essa nova abordagem se organiza em novos paradigmas e, necessariamente, em novos valores. O que importa agora, mais do que determinado conteúdo (já que qualquer saber "acionável” é provisório e circunstancial), é o fluxo dos conteúdos. Para o teórico, nossa capacidade de aprender o que precisamos para amanhã é mais importante do que aquilo que sabemos hoje. Nesse entendimento, o saber se tornou algo que transcende o ser de um "eu”, ampliando-se a ligação de um "nós”, em nós. Em outra ordem de conexão, Katherine Hayles vê os seres humanos e os computadores como parceiros em "heterarquias dinâmicas", ligados por uma dinâmica de intermediação. ParaHayles, emborahajaóvbiasdiferençasemgrau de complexidade "the human and computer are increasingly bound together in complex physical, psychological, econimic, and social

${ }^{2} \mathrm{O}$ conectivismo é a integração de princípios explorados pelo caos, redes e teorias da complexidade e autoorganização. A aprendizagem é um processo que ocorre dentro de ambientes nebulosos onde os elementos centrais estão em mudança - não inteiramente sob o controle do indivíduo. A aprendizagem (definida como conhecimento acionável) pode residir fora de nós mesmos (dentro de uma organização ou um banco de dados), é focada em conectar conjuntos de informações especializados, e as conexões que nos permitem aprender mais são mais importantes que nosso estado atual de conhecimento. (2004).(tradução nossa). 
formations."3(2008, p.47).Tudo indica que ambos, computadores e seres humanos, interagem em intermediação ininterrupta, alterando-se, e - se tudo correr bem melhorando-se entre si, no que pode ser compreendido na seguinte analogia: da mesma maneira que o corpo da mãe forma o feto, o feto reforma o corpo da mãe: "both are boundtogether in a dynamicheterarchy, theculminationofwhichistheemergentcomplexityofan infant."4 (HAYLES, 2008, p. 45).

A mediação ou o agenciamento de dispositivos tecnológicos ganha, no computador, uma função de forte complexidade: a comutação. Para Marc Guillaume, a comutação é responsável pelo agenciamento das relações estabelecidas nos processos de informação e de comunicação, "a pesquisa, o estabelecimento, a manutenção, o rearranjo de conexões entre elementos de um ou de vários conjuntos.” (2010, p. 146). Para o teórico, os meios de comutação de massa, rádio e TV, como mídias irradiantes, com difusão a partir de um centro, são pouco comutativos. O computador, contrariamente, permite a "navegação cômoda e 'inteligente." (GUILLAUME, 2010), com maior poderpara que se mantenham, modifiquem e interrompam as conexões:

\begin{abstract}
O computador é de fato, a tecnologia que dá à comutação todo o seu poder. Em sua simples função de cálculo, ele já estabelece conexões entre números (o termo francês ordinateur, muito mais adequado que computador, é uma feliz variável, inventada pelo professor Legrand, do termo comutador). Estendendo seu funcionamento dos espaços dos números ao dos textos e das imagens, o computador faz nascer o tratamento de texto e, sobretudo, o hipertexto e o hiperdocumento. Dotando um texto ou uma imagem de links que são igualmente conexões potenciais, prepara-se este texto ou esta imagem para comutação com outros documentos. Se se amplia esta comutação a diferentes servidores informáticos, pode-se vincular os hipertextos entre eles para se obter... aweb, espécie de hipertexto mundial que constitui o verdadeiro nascimento da internet para o grande público. (p. 150).
\end{abstract}

Segundo Guillaume, o hipertexto propõe uma inversão radical no que tange à leitura e seus estatutos. Se antes o leitor procurava a informação dentre documentos - e podemos, todos, relembrar (ou talvez, aos mais jovens, imaginar) o trânsito físico dentre livros, na biblioteca, em busca daquela fonte - ao (hiper)leitor basta "anunciar a informação desejada (com uma palavra-chave, por exemplo) e ela é automaticamente dirigida a seu destinatário" (2010, p. 150). Na ordem dessa mudança, em específico entre membro de determinadas comunidades, como a científica, em particular, o ganho de tempo e a produtividade parecem inquestionáveis, quanto mais quando se aperfeiçoa, cada vez mais, a

3 “o ser humano eo computador estão cada vez mais unidos em complexas formações físicas, psicológicas, econômicas e sociais". (tradução nossa).

4 "ambos estão ligados numa heterarquia dinâmica, o ponto culminante de que é a complexidadeemergente de uma criança". (tradução nossa). 
comutação automatizada por meio de "agentes inteligentes" ou de "motores de pesquisa". Para o teórico, a comutação é, em si, atributo das novas mídias, espécie de insígnias da pósmodernidade:

Surgem, então, duas grandes famílias de mídias. As mídias clássicas são as mídias irradiantes (difusão a partir de um centro), pouco comutativas (livros, jornais, rádio e televisão). Elas ficam fáceis de controlar, visto que basta controlar um centro de emissão, e caracterizam a modernidade. As mídias novas, pós-modernas, são as mídias comutativas (telefone, computadores e redes, hipertextos). A comutação, que dá um poder singular à comunicação/informação a distância (é o essencial do aporte da internet e da web), é, indiscutivelmente, o motor das evoluções atuais. (GUILLAUME, 2010, p. 151.).

E essa ordem renovada, na qual a leitura, como ato, sofre uma aguda ruptura com relação à postura "clássica", se imprime ou, melhor, se atualiza em todas as formas de troca, nas organizações comerciais, nos mercados, na moeda, e mesmo nos polos de interconexão dos meios de transporte numa cidade, agora reconfigurada à condição de hipercidade.

$\mathrm{Na}$ tentativa de descrever e de definir as novas mídias, Guillaume propõe, contudo, pontos de reflexão sobre as melhores possibilidades das tecnologias comutativas: "Do bom uso político dos comutadores" e "Do bom uso intelectual das mídias comutativas". No que concerne à política, o tempo é uma expressão-chave. Para o teórico, o tempo histórico e social é longo, envolvido na busca de maturidade num projeto de universalização fundado nos direitos do homem, no direito à diferença, e nos demais princípios do que podemos imaginar como um horizonte comum de civilização, de solidariedade e de justiça. É o tempo que permite o debate, a reflexão, o confronto de valores e a "colocação das escolhas feitas à prova". É, com o tempo, que pensaremos sobre os outros problemas surgidos na pós-modernidade, os quais afetam nossa cidadania, nossa privacidade, nossa convivência nas hipercidades na quais nem sempre se equivalem, entre si, democracia e comunicação.

Sobre a questão intelectual, em específico, refere o teórico que,

\footnotetext{
No que concerne à pesquisa científica e tecnológica, é bastante evidente que a velocidade, o poder, a comodidade das redes informatizadas contribuem para acelerar os progressos. Mais provavelmente para os progressos "ordinários" que para as descobertas fundamentais, que exigem tempo, talvez até solidão, para os pesquisadores que se aventuram fora dos caminhos balizados da pesquisa. (GUILLAUME, 2010, p. 158).
}

Segundo Guillaume, as limitações das ferramentas tecnológicas confrontar-se-iam com a complexidade do conhecimento quando estabelecido fora dos caminhos triviais indicados, por exemplo, por uma pesquisa em sites de busca, por meio de "motores de 
pesquisa".Nesse aspecto, o conhecimento acionável parece se distinguir de um saber estabelecido em bases reflexivas interpretativas, transformadoras, para as quais o dinamismo de uma interação automática é insuficiente, embora não menos útil em determinados momentos ou em determinadas etapas metodológicas de estudo. De forma semelhante, a referência de distintas dimensões no saber talvez se enquadre em outra linha, numa perspectiva que observe distinções de ordem textual e de leitura diante determinada ordem textual. Dessa forma, as descobertas "fundamentais" da ciência talvez se assemelhem à leitura de um texto não ordinário, particular, como o caso do texto literário, o qual também implica que o tempo "pare" ou que se alongue, que o desconforto chegue, que o poder da comutação se atenue à maior sensibilidade possível na contemplação e na reflexão. A solidão talvez seja a outra face de uma prática que exige ao leitor a circunstância não apenas de si, como leitor, mas a circunstância que o texto propõe, como artístico. Não se trata de inventar ou propor um coprodutor no sentido mais superficial do termo - um leitor que interaja com o texto literário com a mesma habilidade e com os mesmos reflexos motores de um jogador de videogames. Não se trata de fazer do leitor um indivíduo de corpo plugado e de mente imersa; não se trata de imaginar um coautor no sentido tradicional da autoria que envolva um parceiro de composição. Trata-se de desenvolver ou mesmo permitir que haja contemplação na tela de algo que já foi "feito", o texto literário, e de se aceitar que a atitude leitora também transgrida e mesmo "modifique” o já "feito". Essa é, afinal, embora todas as exigências e habilidades necessárias para leitura da literatura eletrônica, como vista por Katherine Hayles (2008), a possível essência de um texto literário na tela:

[...] computation evolves into something more than a technical practice, though of course it is also that. It becomes a powerful way to reveal to us the implications of our contemporary situation, creating revelations that work both within and beneath conscious thought. Joining technical practice with artistic creation, computation is revalued into a performance that address us with the full complexity our human nature require, including the rationality of the conscious mind, the embodied response that joins cognition and emotion, and the operates through sedimented routines of habitual actions, gestures, and postures. This understood, computation ceases to be a technical practice best left to software engineers and computer scientist and instead becomes a partner in the coevolving dynamics through which artists and programmers, users anda players, continue to explore and experience the intermediating dynamics that let us understand 
who we have been, who we are, and who we might become. ${ }^{5}$ (p.157).

No entanto, para entendermos o que somos, é preciso tempo. Para sentirmos o peso de nossos pensamentos mais escondidos, de nossas angústias ocultas, devemos recompor a ilha na qual, às vezes, nos vemos naufragados, nós mesmos. Para ler é preciso mais do que ligar, é saber que o mouse é realmente o que deve ser, um periférico, não o centro ou a saída. Nesse sentido, mesmo o twiter pode exigir mais do que a breve interação com o curto intervalo de um enunciado de 140 caracteres; pode exigir leitura profunda. É o que se pode perceber em alguns dos aproximadamente 4.600tweets de Fabrício Carpinejar para seus mais de cem milfollowers. Pelo aforismo, Carpinejar fala sobre a verdade e a mentira:

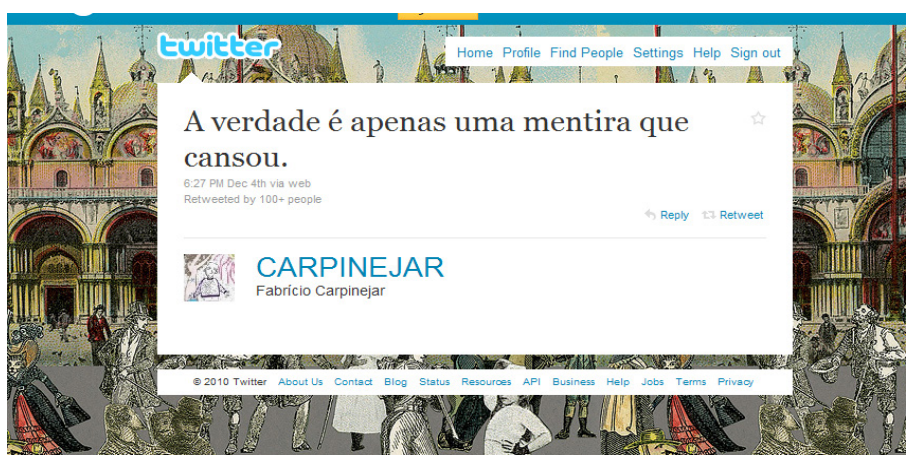

Figura 1. A verdade de Carpinejar

Remete à saudade e às recaídas do amor:

\footnotetext{
5“a computação evolui para algo mais do que uma prática técnica, embora, naturalmente, também seja isso. Ela se torna um meio poderoso para nos revelar as implicações de nossa situação contemporânea, criando revelações que trabalham dentro e abaixo do pensamento consciente. Unindo a prática técnica com a criação artística, a computação é reavaliada (ou revalorizada) em uma performance que nos trata com toda a complexidade de nossa natureza humana requer, incluindo a racionalidade da mente consciente, a resposta incorporada que se junta à cognição e à emoção, e opera através de rotinas sedimentadas de ações, gestos e posturas. Assim entendida, a computação cessa de ser uma prática técnica que deve ser deixada para engenheiros de software e cientista da computação e, em vez disso, se torna um parceiro em dinâmica coevolução através da qual artistas e programadores, usuários e jogadores, continuam a explorar e conhecer a dinâmica de intermediação que nos permite entender quem nós fomos, quem somos, e o que possamos nos tornar." (tradução nossa).
} 


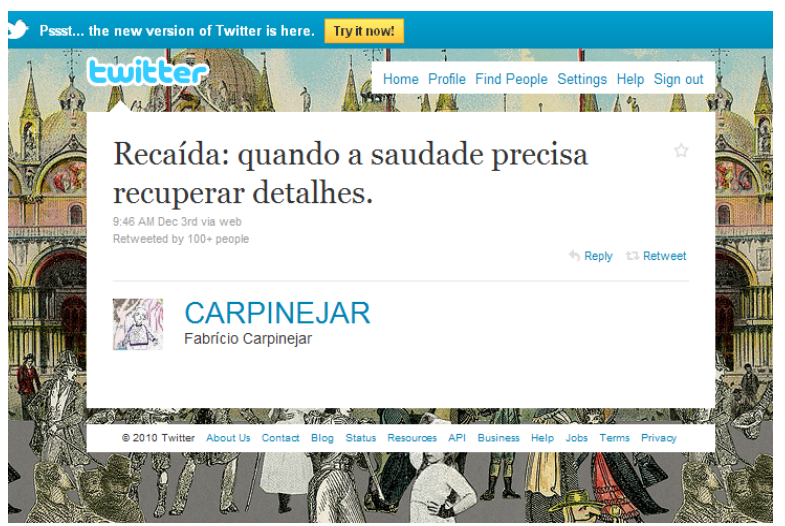

Figura 2. As recaídas de Carpinejar

Dá nova condição à infelicidade (rindo dela e dos “infelizes”):

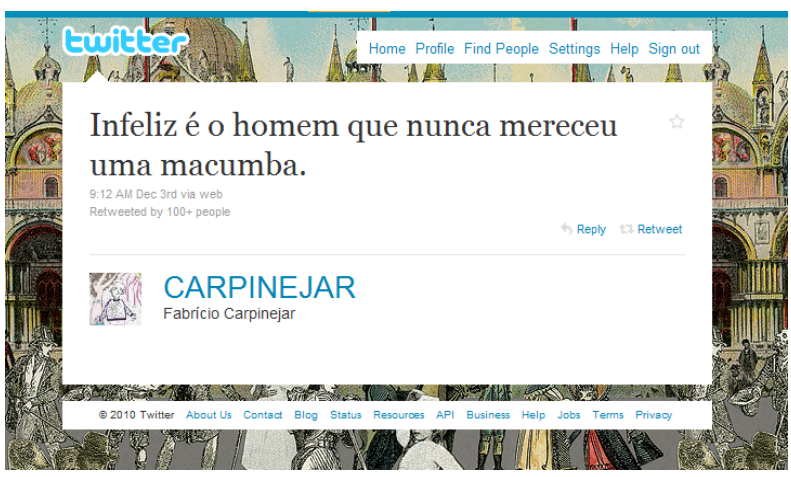

Figura 3. Infelicidade masculina e macumba

Há, nesses textos, embora de tamanho diminuto, o que se pretende ao leitor de uma coautoria no sentido de um jogo em combinação e recombinação,de links que se acionam de e por dentro do leitor, em nós, leitores, não na página seguinte do hipertexto digital. Wolfgang Iser propõe a figura do jogo no momento em que os espaços vazios do texto convocam movimentos performativos necessários à leitura e ao leitor. Na dualidade inerente ao próprio jogo, para o qual é essencial tanto remover as oposições (diferenças) quanto mantê-las - a fim de que o jogo mesmo exista - cabe ao leitor ressignificar uma espécie de lapso fundamental de todo significante envolvido nesse jogo. O significante no jogo do texto literário é refém de uma circunstância na qual está em conflito sua função designante: ele ao mesmo tempo denota e nega seu uso denotativo. Dessa forma, esse significante, simultaneamente denotativo e figurativo, deve ser "resolvido" ou deve invocar "alguma coisa que não é pré-dada pelo texto, mas engendrado por ele, que habilita o leitor a dotá-lo de uma forma tangível." (ISER, 2002, p. 110).

Nesses pequenos textos, os "significantes fraturados", abertos, precisam de entrada em jogo da leitura de alguém; nesses pequenos textos, os esquemas, por si contraventores, 
por serem artísticos, devem ser novamente subvertidos pelo olhar contemplativo que faz e refaz, modela e remodela sentidos, segundo suas inclinações, embora as funções originais nunca sejam totalmente suspensas, em nome de não se encerrar o jogo definitivamente com o fim do texto e a supremacia da leitura. $\mathrm{O}$ impasse deve permanecer: a verdade como se fosse uma mentira; o amor, doença sem cura, reincidida pela saudade; o feitiço, ventura e fortuna. Tudo como se fosse sem verdadeiramente ser.

De outra maneira, no twitter, Carpinejar redireciona o leitor para uma carta de amor à esposa (de verdade, de mentira que cansou?), publicada numa revista feminina e disponível no seu blog. Para pensar na vida e, sobretudo, falar de amor, podemos precisar de mais de 140 caracteres:

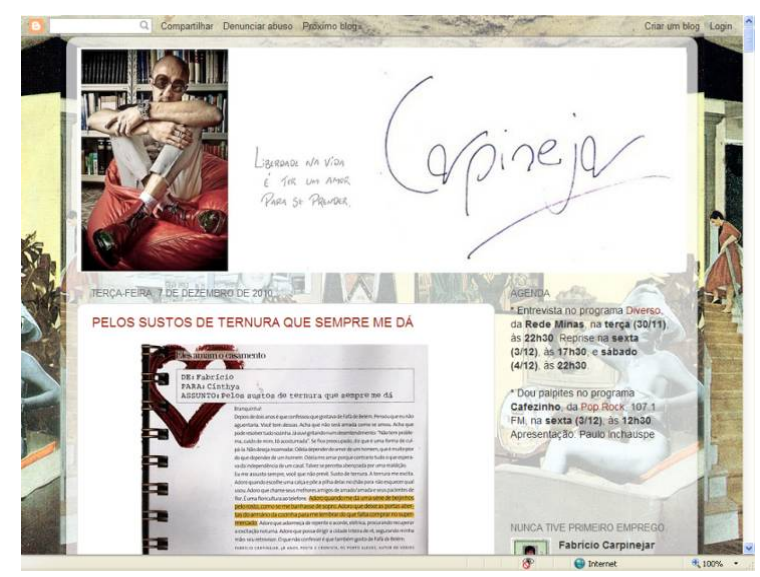

Figura 4. Blog de Carpinejar

$\mathrm{Na}$ carta, as coisas simples e as coisas muito importantes, como gostar de Fafá de Belém, revelam o amor do diaadia, a felicidade dos pequenos conflitos, as dificuldades da dependência do outro:

Depois de dois anos é que confessou que gostava de Fafá de Belém. Pensou que eu não aguentaria. Você tem dessas. Acha que não será amada como se amou. Acha que pode resolver tudo sozinha. Já ouvi gritando num desentendimento: "Não tem problema, cuido de mim, tô acostumada". Se fico preocupado, diz que é uma forma de culpá-la. Não deseja incomodar. Odeia depender do amor de um homem, que é muito pior do que depender de um homem. Odeia me amar porque contrario tudo o que esperava da independência de um casal. Talvez se perceba abençoada por uma maldição. Eu me assusto sempre, você que não prevê.[...] Adoro quando me dá uma série de beijinhos pelo rosto, como se me banhasse de sopro. Adoro que deixa as portas abertas do armário da cozinha para me lembrar do que falta comprar no mercado. Adoro que adormece de repente e acorde, elétrica, procurando recuperar a excitação noturna. Adoro que pode dirigir a cidade inteira de ré, segurando minha mão: seu retrovisor. $\mathrm{O}$ que também não confessei é que gosto de Fafá de Belém.(CARPINEJAR, blog, 7 de dezembro). 
Perante as exasperações, os “ódios” diários e característicos do sujeito a quem ama, diante das várias negativas desse amor abençoado por uma maldição, o "eu" da carta de amor de Carpinejar reitera adorações singelas e candentes e se confessa, acima de tudo se confessa, após uma outra confissão desse amor, após dois anos... há um tempo para confessar também.

Em outras produções literárias, o tempo é o tema, embora revestido de outros sentidos. É caso de outro tweet, que faz migrar, em link, não para um blog, mas para umminimetragem. É do coletivo "Sem ruído", que tem em torno de 2.300 seguidores e se propõe escrever “(quase) um microconto por dia”. O grupo é formado por sete jovens, com a liderança do estudante santista Ian Leite, de aproximadamente vinte anos. O vídeoacompanha um texto. Nessa combinação de imagem, som e palavra escrita, há a dolorosa angústia de vencer o tempo, o sono, a parada. No fim de tudo, a erupção de um café no bule.

Param. As duas. Horas. As duas horas. Não param, param? Quem? As horas não param, as duas horas. Gole. Dormir é improdutivo. Goles. O produto produzido para produzir. Outro. Outro gole. O tempo não pára. Taquicardia. Otemponãopára. Sudorese. Produtoproduzidoparaproduzir. Cafeína. Cafeína. Cafeína... (In: Cafeina)

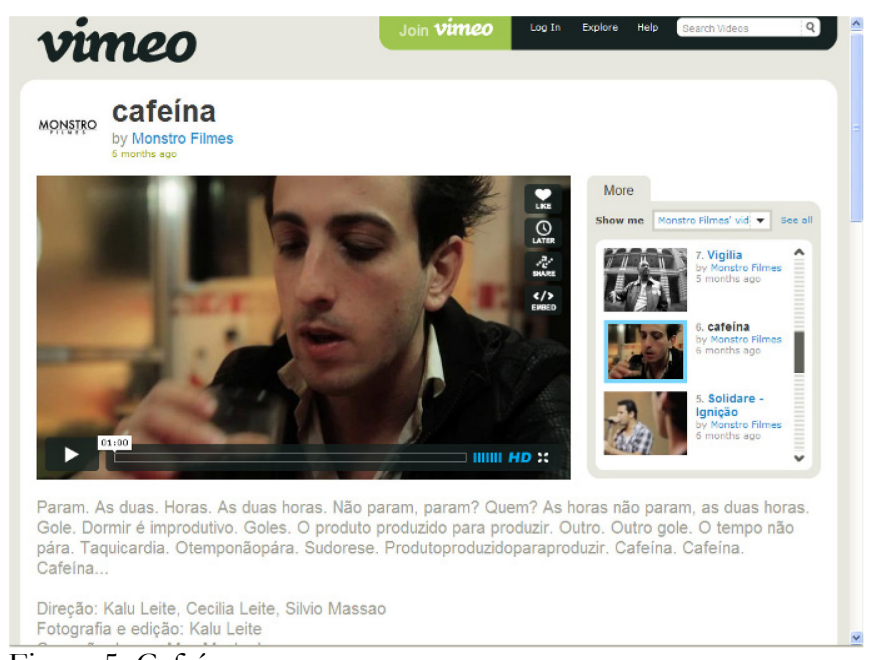

Figura 5. Cafeína

Em jogo está, no suporte por excelência da conexão e da comutação, o questionamento ao universo multi e hiperestimulado, cafeinado, que nunca dorme e que sempre muda. "As horas não param", toda parada é improdutiva, tão improdutiva quanto o que se pode atribuir mesmo ao prazer estético e à leitura, para os quais e com os quais não se "faz" nada. Sem sudorese não há produto e essa vigília já não separa os termos. Tudo 
está colado, "Produtoproduzidoparaproduzir", tudo perde a pausa, o intervalo entre as palavras, o intervalo entre os opostos em jogo, a distância entre o contraditório, a separação entre os sentidos, a abertura designante. Tudo fecha.

Obviamente que exemplos de coautoria "ativa" nas telas não faltam ou faltarão. Há uma hiperliteratura interativa ou uma literatura eletrônica ainda incipiente na rede. É o caso dos textos "telescópicos" deJoe Davis (http://www.telescopictext.org), um tipo de narrativa, de código e de texto que consiste num conjunto de ferramentas o qual permite a expansão e a ampliação de palavras, de expressões e de textos. Nessa narrativa, o jogo está em entrar, como com um telescópico, dentro da palavra, ampliando seu significado ao adicionar à leitura dos termos perspectivas ou detalhes antes invisíveis. $O$ texto abaixo(Figura 6)surgiu da mínima oração "I madetea.".

\section{I boiled the kettle. The kettle grumbled so I poured water onto a teabag and watched it brew. I removed the teabag, then flicked it into the bin. I picked up my mug and left the kitchen with a cup of strong tea.}

by Joe Davis >

Figura 6. Texto expandido de Joe Davis

Sujeitos em conexão na rede de computadores e tecnologias comutativas são facetas da pós-modernidade, ou de como se queira chamar a atualidade. Há, contudo, o perigo de que tudo se queira transformado em necessidade de imersão na web, de percurso constante, ininterrupto, insone pelos links. Marc Guillaume observa as diferenças no fluxo de dados e de informações em contrapartida com o que pretende entender como "saber". Para ele, a leitura e a assimilação de conhecimentos novos "demandam sempre tanto tempo e esforço hoje quanto no passado" e, nesse sentido, "as interfaces técnicas só podem facilitar em certos casos e em medida limitada." (GUILLAUME, 2010, p. 156). Assim, as interfaces podem facilitar o acesso, o que não quer dizer que isso ocorra de forma igualitária ou semelhante:" $a$ lógica de distribuição dos objetos culturais periga ser estruturalmente incompatível com, dentre eles, aqueles cuja difusão, ao menos num primeiro momento, é mais lenta e mais difícil” (GUILLAUME, 2010, p. 159). No caso específico da leitura literária, a velocidade não é um facilitador. Pelo contrário, é um obstáculo entre os nós: aquele que corresponde ao autor, aquele que corresponde ao texto, esteja ele na matéria dos átomos ou na potência dos bits, e, principalmente, aquele que 
corresponde ao leitor. Iser, observando a constituição antropológica do jogo, observa o quanto nos ajuda a "captar o que somos" (ISER, 2002, p. 110), mas isso implica, na leitura, nesse jogo, muito mais um ato de deslocamento e desfiguração do que de internalização de esquemas ou, se quisermos, de um sistema. É o que permite estarmos em nós mesmos, não nos nós da rede hipertextual, ou nos nós dos coletivos, mas nos nós de nossa própria subjetividade silenciosa.

\section{Referências}

GUILLAUME, Marc. A revolução comutativa. In: PARENTE, André (Org.). Tramas da rede. Porto Alegre: Sulina, 2010.

HAYLES, Katherine.Electronic literature.New horizons for the literary.UniversityofNotreDame. 2008

ISER, Wolfgang. O jogo do texto. In: LIMA, Luiz Costa. A literatura e o leitor. Textos de estética da recepção. 2. ed. São Paulo: Paz e Terra: 2002.

LÉVY, Pierre. O que é o virtual? São Paulo: Ed. 34, 1996.

SANTOS, Alckmar. Leituras de nós. Ciberespaço e literatura. São Paulo: Itaú Cultural, 2003.

SIEMENS, George. Connectivism: a learning theory for the digital age. Disponível em http://www.elearnspace.org/Articles/connectivism.htm. Acesso em 20 nov.2008.

http://carpinejar.blogspot.com

http://twitter.com/CARPINEJAR

http://twitter.com/semruido

http://vimeo.com/12579606

http://www.telescopictext.org 